\title{
Through the Wall
}

\section{Edited by Annie Buckley and Matthew McMilon}

San Bernardino: Prison Arts Collective, California State University, San Bernardino

\section{Reviewed by Jonathan Cummins}

Through the Wall (2016), a richly illustrated book, showcases the work of artists and writers incarcerated in three prisons in California, all of whom are participants in the Prison Arts Collective (PAC) arts programme. This innovative university-led initiative provides visual art, art history and creative writing programmes to prisoners at California Institution for Men (Chino), California Institution for Women (Chino) and California Institution Los Angeles County. PAC is part of California State University San Bernardino (CSUSB) Community-based Art (CBA), an extensive programme dedicated to expanding access to the arts in settings that rarely promote arts education such as after-school programmes for at-risk children, shelters for youth and prisons.

The book was produced to accompany a 2016 exhibition of the same name at CB1, a contemporary art gallery in Los Angeles; yet it confidently functions as a standalone publication to introduce the diverse work of the artists involved. In keeping with what PAC describe as their collaborative and non-hierarchical ethos, the book documents the work of highly motivated self-taught artists, who engage with the programme through advanced critique classes, alongside artists who have only embarked recently on their art practice. The publication is edited by Annie Buckley and Matthew McMilon. Buckley is founder and director of CSUSB-CBA and PAC and associate professor of Visual Studies at CSUSB while McMilon is a teaching artist with PAC and Master of Fine Art candidate at CSUSB.

Context for the book's two-hundred plus illustrations is provided through a short introduction by Buckley, a foreword by artist-participant Stan Hunter and further texts by participant artists, teaching artists and associated staff. These short texts help situate the pieces and give context to the day to day working methods employed in what seems to be a very successful and dynamic studio-based prison arts programme. In his foreword, artist and PAC participant Stan Hunter emotively spells out the wide-ranging and positive impact that art has played in his twenty-eight years in prison. What is clear from the paintings, art objects and poems documented in the book is that when a prisoner is painting or writing, he or she is first and foremost an artist. The work in this book clearly illustrates the ways in which art allows us to reframe experience and identity, which is particularly important in the prison context.

The artworks created at each facility reflect particular themes and styles but a shared culture of studio production, critical thinking and group engagement is evident across the three facilities. Many of the artworks documented in the book depict idealised images of nature which are articulated with great skill and sensitivity. Nonetheless, isolation and the reality of prison life is a constant theme. Rarely, for example, do the artworks bear witness to social engagement and relatedness to other. Figures are frequently depicted alone such as Hooker's 'Mprisoned' or C. Weyant's 'Lonely Man 2'. This is work about 'doing time' and the poems and artworks provide a visceral engagement and commentary on the prison context from which they emerge. D. Eagen and J. Tercero's austere paintings of prison, for example, sit in stark contrast to S. Hunter's verdant paintings of nature such as 'Paradise' and 'Peace' or L. Valencia's many paintings of dolphins breaking the waves. Like different sides of the same coin, the heightened representations of nature provide a counterpoint to the contained, surveyed and censored life of prison. This gulf between 'inside' and 'outside' worlds points to the enormous personal challenges involved in maintaining one's identity while incarcerated and the difficulty in mediating relationships with loved ones on the outside as the years go by. 
Despite the context, there is playfulness and joy in the paintings such as R. Yovano's 'Untitled' series of circus animals and the collaborative project 'Community Quilt'. There is a lively commentary around contemporary politics such as E. Gonzalez' 'The Antichrist', which comments on President Trump's stance on walls between the United States and Mexico. An important aspect of the programme is that it enables prisoners to create an artwork that can be gifted to a family member on the outside. This allows a man or woman on the inside to present a different side of self to those who really matter in his or her life. This simple but important act of exchange is evident in the content of many of the artworks, which express themes of home and longing.

Having worked as an art tutor in a prison in Ireland for many years, I'm particularly interested in those texts that detail the day to day methods employed by teaching artists, site leads and participants. It is clear that PAC has successfully created and sustained a positive group studio teaching environment, which is a very real challenge in prison. The process of art making provides participants with an experience and sense of place that is somewhat independent of the security regime and one which I expect provides a powerful normalising influence in the closed and contested nature of prison life. The book, like the public exhibition it accompanies, plays an important role in bridging worlds of inside and outside. It also represents a critical part of the art-making process; the public exhibition and dissemination of art enables the artist-participant to be a full artist by allowing others to experience their work.

PAC presents a model of how universities and prison institutions can work in partnership to create an environment of mutual learning. This is a relationship that works both ways. CSUSB-PAC, by facilitating students to teach in prisons through internship on credit-bearing modules, creates a mechanism for educating and fostering socially aware art teachers and artists who can engage meaningfully with individuals, groups and institutions. This inter-related process creates an experience that embeds itself deeply in the visiting teaching artist as much as the incarcerated artist. The book bears witness to the depth and breadth of the work being created by artists in prisons in California and the important arts education programmes provided by PAC.

Jonathan Cummins is a lecturer at the Belfast School of Art, Ulster University, Northern Ireland, and a former lecturer in the National College of Art and Design (NCAD) Prison Art Progamme (Portlaoise Prison), Ireland. 